\section{Medizin, personalisierte}

\section{J. Arnemann}

Abteilung Molekulargenetik, Labor Dr. Wisplinghoff, Köln, Deutschland

Synonym(e) Individuelle Krankheitsbehandlung

Englischer Begriff personalised medicine

Definition Unter personalisierter oder individualisierter Medizin versteht man vordergründig ein alternatives Behandlungskonzept, das individuelle Gegebenheiten, spezielles Krankheitsbild, Nachweis definierter Biomarker und Genmutationen zur Auswahl einer maßgeschneiderten Pharmakotherapie heranzieht.

Beschreibung Den größten therapeutischen Einfluss hat die personalisierte Medizin auf dem Gebiet der Onkologie. Hier werden oftmals vor einer Behandlung die Tumorbiopsien der Patienten molekulargenetisch auf HotSpot-Mutationen in tumorspezifischen Signal- und Regulationsgenen analysiert, deren Ergebnisse unmittelbar das Therapieschema bedingen. Relevante Gene sind u. a. BRAF (u. a. Melanom), EGFR (u. a. Lungenkarzinom), KRAS, NRAS (u. a. KolonKarzinom), EML-ALK (Lungenkarzinom) oder BRCA1/2 (Ovarialkarzinom).

Ein weiterer, wichtiger Aspekt der personalisierten Medizin ist, dass bei Veränderungen des Befindens oder klinischer Parameter unter der Therapie eine Überprüfung der Biomarker erfolgt, oftmals durch $>$ Next-Generation-Sequencing (NGS), um für die medikamentöse Therapie relevante Sekundär- oder Resistenzmutationen zu identifizieren. In der Erprobung sind hierfür sog. Liquid-Biopsies, mit deren Hilfe aus Blut-, Stuhl- oder Urinproben zirkulierende Tumorzellen (ctcDNA) oder auch zellfreie DNA (cfDNA) isoliert und analysiert werden.

\section{Literatur}

Richter-Kuhlmann E (2012) Personalisierte Medizin: Erst am Anfang des Weges. Dtsch Ärztebl 109:A-1305 